Entrevista sobre "Derrota. Los sonidos de la guerra". Podcast - Serie sonora

Carlos José Giordano

Question/Cuestión, Nro.70, Vol.3, diciembre 2021

ISSN: 1669-6581

URL de la Revista: https://perio.unlp.edu.ar/ojs/index.php/question/

IICom -FPyCS -UNLP

DOI: https//doi.org/10.24215/16696581e611

\title{
Entrevista sobre
}

"Derrota. Los sonidos de la guerra"

Podcast - Serie sonora

\section{Interview about}

"Defeat. The sounds of war"

Podcast - Sound Series

Carlos José Giordano

Instituto de Investigaciones en Comunicación; Facultad de Periodismo y Comunicación Social; Universidad Nacional de La Plata

Argentina

carlos.giordano@presi.unlp.edu.ar / cjgior@gmail.com

https://orcid.org/0000-0003-3345-3041 


\section{Resumen}

En forma complementaria a la presentación de la serie sonora/podcast "Derrota. Los sonidos de la guerra", produjimos un diálogo con Carlos Milito, Tomás Porta, Juan Milito y Camilo Giordano. Usamos el soporte virtual audiovisual de la plataforma Zoom. Al final de la siguiente presentación, se la puede escuchar completa.

Palabras clave: Derrota, Comunicación, Guerra, Podcast, Poesía, Malvinas

\section{Abstract}

In a complementary way to the presentation of the sound series / podcast "Defeat. The sounds of war", we produced a dialogue with Carlos Milito, Tomás Porta, Juan Milito and Camilo Giordano. We use the virtual audiovisual support of the Zoom platform. At the end of the next presentation, it can be heard in full.

Keywords: Defeat, Communication, War, Podcast, Poetry, Malvinas

\section{Comunicación/Guerra}

- Es un Programa de Investigación donde conjugamos el análisis sobre los Medios y las Mediaciones que suceden en los momentos y territorios donde se producen las Guerras. Lo histórico y lo conceptual. Procesos y significantes.

- Estos análisis los hacemos desde todos los "soportes" tecnológicos y lingüísticos: los distintos modos de las expresiones gráficas sobre superficies físicas miméticas, los sonoros, los audiovisuales, los multimediáticos y los transmedia.

- Tomamos "casos" y los abordamos desde procesos productivos que posibiliten su comunicación integral, activa, militante y consecuente con las ideas modernas de lo 
democrático en nuestra contemporaneidad política: Memoria - Verdad - Justicia Soberanía - Paz.

- La situamos como parte de las contribuciones sociales, culturales y políticas que hace/hacemos en nuestra sociedad para con la obra del CECIM-La Plata, bajo nuestra entera responsabilidad.

- En esta ocasión, frente a la efeméride del final de las acciones bélicas por Malvinas en 1982, hemos elegido hacerlo como una comunicación transpoética: "Derrota. Los sonidos de la guerra".

1. "Derrota significa, por un lado, el trayecto/rumbo que "en realidad" sigue una embarcación -distinto del proyectado- debido a corrientes, vientos, errores instrumentales, etc., pero también implica salir "vencido" en un conflicto bélico..."

2. "La derrota es "la retirada desordenada de un ejército vencido". No sólo, y no exclusivamente, la victoria del otro... supone la disolución de una tropa, su dispersión y la incapacidad de rehacerse para retomar el combate".

3. "La derrota siempre proviene de, y produce, un descalabro... pero también puede producirse sin un motivo bélico aparente que la justifique, quizás por desaciertos y contradicciones en el mando, de cansancios o privaciones injustificadas y de noticias 0 rumores desfavorables...

4. La derrota en Malvinas, entonces. Ese rumbo seguido "en realidad", ese salir vencido: la poética de los sonidos como una forma de no continuar la guerra por otros medios, por todos los medios y las mediaciones.

5. Con estas definiciones primeras y primarias, presentamos esta comunicación transpoética que junta cuatro tipos de pruebas sobre el poder del sonido para dar cuenta de la guerra, por ejemplo.

6. Fraseos, discursos, relatos y músicas son los hilos de esta trama que nos sostiene en vilo para poder decir qué nos sigue pasando cuando pensamos la guerra, pero sobre todo la derrota. En esta ocasión, las de Malvinas: la guerra y la derrota. 


\section{Enlace directos a la escucha}

- $\quad$ https://soniicom.wordpress.com/2021/10/13/derrota-los-sonidos-de-la-guerra/

- https://open.spotify.com/show/4Ogh9HR7z9gFPQy84LYRnm?si=3hRfBXCyTxGEa5Tc aQqbyw\&utm source=whatsapp

\section{Créditos}

- Paula Porta, Subdirectora del Instituto de Investigaciones en Comunicación de la Facultad de Periodismo y Comunicación Social de la Universidad Nacional de La Plata, encuadra esta serie en el Programa "Comunicación/Guerra" creado y producido con emoción y compromiso patriótico.

- Las Voces:

- Sostiene toda la estructura: Julieta Vallina

- Compone el análisis de Vicente Zito Lema: Manuel Callau

- Leen sus poesías:

- Luis Aparicio

- Gustavo Caso Rosendi

- Carlos Giordano

- Martín Raninqueo

- Alejandro Villanueva

- Manuel Giordano lee a Javier Serrano, quien murió en las nieblas de la posguerra

Los sonidos documentales son de periodistas, locutores, militares/genocidas/terroristas, familiares y sobrevivientes, contemporáneos de los días y el proceso de la guerra de Malvinas.

La canción "Comunicado 166" es de Los Violadores y hemos usado un fragmento en su homenaje.

- Edición: Juan José Montero

- Dirección: Carlos Milito y Carlos Giordano 
Question/Cuestión, Vol. 3, № 70

Diciembre 2021

ISSN 1669-6581

14 de junio de 2021, a 39 años: Memoria - Verdad - Justicia - Soberanía - Paz 